\title{
The role of the emergency medical dispatch centre (EMDC) and prehospital emergency care safety: results from an incident report (IR) system
}

\author{
Alberto Mortaro, MD*; Diana Pascu, MD, MS ${ }^{\dagger}$; Tamara Zerman, MD, $\mathrm{PhD}^{\dagger}$; Enrico Vallaperta, $\mathrm{RN}^{\dagger}$; \\ Alberto Schönsberg, $\mathrm{MD}^{\dagger}$; Stefano Tardivo, MD*; Serena Pancheri, MD, PhD*; Gabriele Romano, MD*; \\ Francesca Moretti, MD, PhD**
}

\section{ABSTRACT}

Introduction: The role of the emergency medical dispatch centre $(E M D C)$ is essential to ensure coordinated and safe prehospital care. The aim of this study was to implement an incident report (IR) system in prehospital emergency care management with a view to detecting errors occurring in this setting and guiding the implementation of safety improvement initiatives.

Methods: An ad hoc IR form for the prehospital setting was developed and implemented within the EMDC of Verona. The form included six phases (from the emergency call to hospital admission) with the relevant list of potential error modes (30 items). This descriptive observational study considered the results from 268 consecutive days between February and November 2010.

Results: During the study period, 161 error modes were detected. The majority of these errors occurred in the resource allocation and timing phase $(34.2 \%)$ and in the dispatch phase $(31.0 \%)$. Most of the errors were due to human factors $(77.6 \%)$, and almost half of them were classified as either moderate $(27.9 \%)$ or severe $(19.9 \%)$. These results guided the implementation of specific corrective actions, such as the adoption of a more efficient Medical Priority Dispatch System and the development of educational initiatives targeted at both EMDC staff and the population.

Conclusions: Despite the intrinsic limits of IR methodology, results suggest how the implementation of an IR system dedicated to the emergency prehospital setting can act as a major driver for the development of a "learning organization" and improve both efficacy and safety of first aid care.

\section{RÉSUMÉ}

Introduction: Le centre de répartition des services médicaux d'urgence (CRSMU) joue un rôle essentiel dans la coordination et la prestation de soins préhospitaliers sécuritaires. Les auteurs, dans l'étude décrite ici, avaient pour but de mettre en application un programme de déclaration des incidents (DI) survenus au cours de la prestation de soins d'urgence préhospitaliers, en vue de relever les erreurs commises dans le contexte et de guider la mise en œuvre d'initiatives visant à améliorer la sécurité.

Méthode: Un formulaire de DI, conçu spécialement pour la prestation de soins en milieu préhospitalier a été élaboré, puis appliqué au CRSMU de Vérone (Italie). Le formulaire comptait six phases (depuis l'appel d'urgence jusqu'à l'admission à I'hôpital), et chacune était accompagnée d'une liste pertinente de types possibles d'erreurs (30 au total). Cette étude descriptive, observationnelle portait sur les résultats enregistrés pendant 268 jours consécutifs, entre février et novembre 2010.

Résultats: Durant la période à l'étude, 161 types d'erreur ont été décelés. Ceux-ci se sont produits en majorité durant la phase de l'affectation des ressources et de la détermination du moment propice $(34,2 \%)$ ainsi que durant la phase d'acheminement $(31,0 \%)$. La plupart des erreurs étaient attribuables à des facteurs humains $(77,6 \%)$, et presque la moitié d'entre elles ont été classées modérées $(27,9 \%)$ ou graves (19,9\%). Les résultats obtenus ont guidé la mise en œuvre de mesures correctrices appropriées, telles que l'adoption d'un système plus efficace de régulation des priorités médicales et l'élaboration d'initiatives de formation ciblant tant le personnel du centre de répartition que la population.

Conclusions: Malgré les faiblesses inhérentes au programme de $\mathrm{DI}$, les résultats semblent montrer comment la mise en œuvre d'un tel programme, réservé à la prestation de soins d'urgence en milieu préhospitalier peut agir comme une force importante de stimulation dans le développement d'une organisation " intelligente ", et peut améliorer à la fois l'efficacité et la sécurité des premiers soins.

Keywords: incident reporting, patient safety, prehospital emergency care, quality improvement, risk management

From the *Department of Public Health and Community Medicine, University of Verona, Italy; †Health Care Trust 20, Verona, Italy; and $\ddagger$ Dipartimento di Igiene e Sanità Pubblica, Sezione di Igiene e Medicina Preventiva, Verona, Italy.

Correspondence to: Dr. Francesca Moretti, Dipartimento di Igiene e Sanità Pubblica, Sezione di Igiene e Medicina Preventiva, Piazzale L.A. Scuro 10, 37134 Verona (VR), Italy; Email: francesca.moretti76@gmail.com 


\section{INTRODUCTION}

Out-of-hospital emergency medical care is a very dynamic and complex environment. Personnel working in this setting have to struggle with time constraints and with acute patient conditions potentially subject to unpredictable changes. ${ }^{1}$ In order to ensure faster and safer provision of emergency care, rescue operations must be coordinated. This coordination is carried out in Italy by the emergency medical dispatch centre (EMDC). ${ }^{2,3}$

In order to prevent serious patient harm, it is essential to better identify and understand the potential failures in the coordination of rescue operation processes. $^{3,4,5}$ Strong evidence on this topic is still lacking, as shown by a recent systematic literature review on patient safety in emergency medical services (EMS). ${ }^{6}$ As suggested by the authors, a key priority is to develop a high-quality self-reporting system that can shed light on adverse events (AE) occurring in EMDC coordination, and guide future interventional research.

Implementing such a system needs a strong safety culture. Literature shows wide variation in safety culture for this setting, evidencing the need to develop more insights into prehospital safety issues. ${ }^{7}$

The main aim of this study was to promote the implementation of an incident report (IR) system in the prehospital emergency care setting in Verona, and to analyse the preliminary results in order to identify main error types and to guide the implementation of safety improvement initiatives.

To our knowledge, this is the first study of its kind in Italy and one of the very few internationally.

\section{METHODS}

\section{Setting}

The study took place at the EMDC of Verona, Italy. The Italian EMS, part of the National Health Care System and based on a public universalistic approach, adopts a stay-and-play model and is structured in a network of services, normally organized on a provincial basis $^{8}$ :

1) The EMDC, which receives all medical emergency service calls (with a dedicated phone number, i.e., 118) and coordinates rescue operations across the local community 24 hours, 7 days a week
2) The community-based first aid system, including the various types of emergency vehicles available across the community, and which is responsible for providing prehospital emergency care

3) A number of hospital services, capable of meeting different health care needs, organized as a hub-andspoke hospital network

The EMDC has a hierarchical organization, including:

- Chief medical director coordinating all activities

- Two (2) physicians responsible for appropriate onsite operations

- Chief nurse coordinating the nursing personnel

- Twenty-three (23) nurses as both dispatchers and active rescuers on the field

Vehicles differ according to the personnel onboard: basic life support ambulances (with only rescue or volunteer personnel), intermediate rescue ambulances (with both rescue and nursing personnel), advanced rescue ambulances (with rescue, nursing, and medical personnel), and a helicopter (with a specialized rescue team, comprising nurses and intensive care physicians). ${ }^{9,10}$

The EMDC of the Province of Verona (part of the National Health Service [NHS] Trust 20 of Verona) covers an area of $3,121 \mathrm{sq} \mathrm{km}$, with a population of over 921,000 inhabitants, served by eight public hospitals belonging to three local NHS trusts and one hospital NHS trust, and by two private hospitals providing services to the NHS.

The system manages over 30 community first-aid stations, located in hospitals, emergency departments (EDs), charities, private providers, and the Mountain Rescue Station of Verona. Figure 1 shows the EMDC calls management process.

\section{Population}

All of the staff working at the EMDC were invited to participate in the study. The staff included 20 nurses (6 female and 14 male) and 3 physicians (all male). The average age was 43.4 years (range $34-57$ ).

\section{Tool}

System failures occurring within the EMDC of Verona were detected through an IR form (i.e., EMS failure report form), specifically developed for this setting by a 


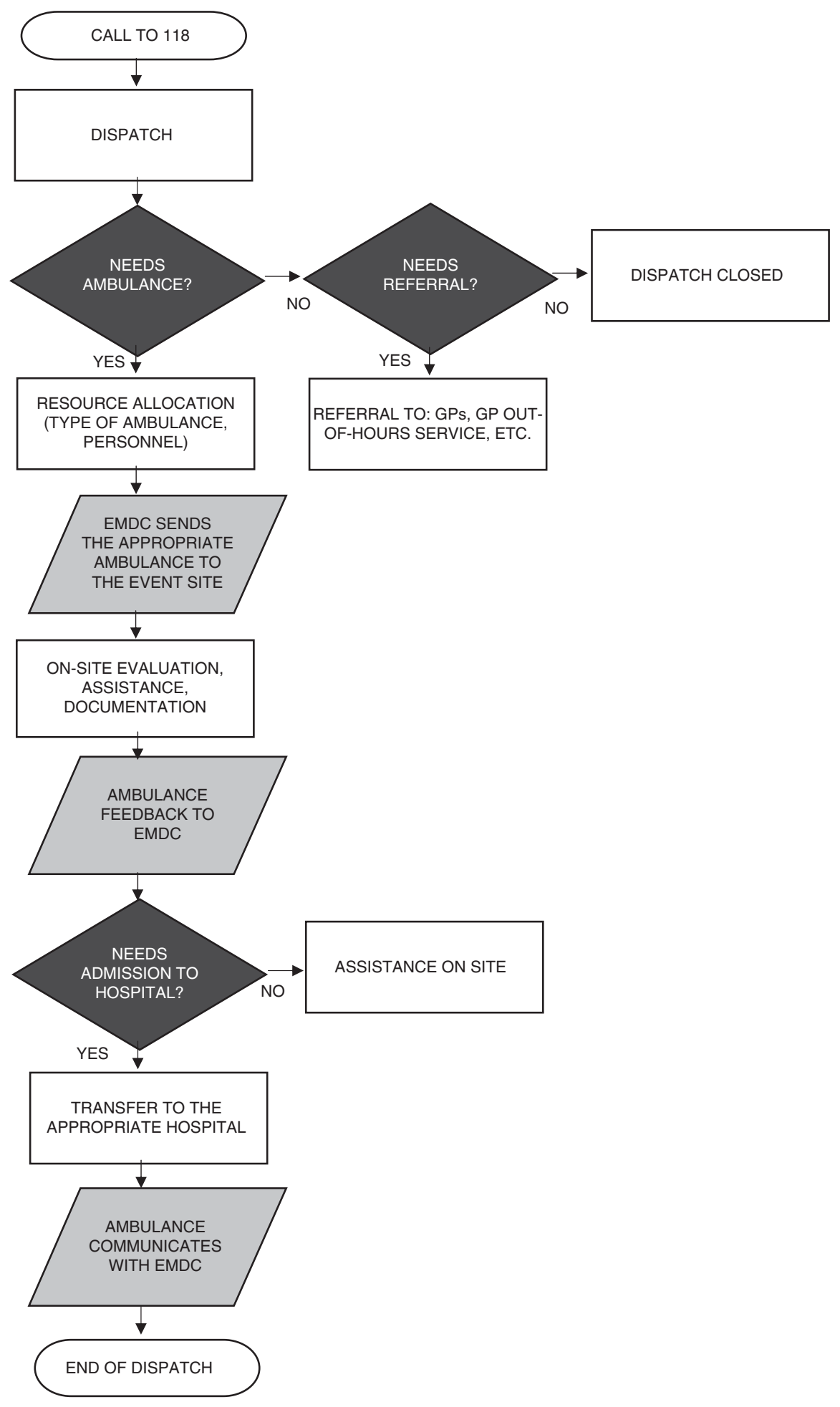

Figure 1. The EMDC calls management process.

group of nurses and physicians in order to guide staff in reporting main system failures and to promote adequate data collection on identified critical areas. System failures were defined as "any error occurring during the whole rescue operation process that results in or could result in patient harm." This definition includes both $\mathrm{AE}$ and near-miss events. It was considered that reporting near misses would have been easier for staff; 
moreover, some $\mathrm{AE}$ are not visible to EMDC staff, because they might occur after patient admission to the hospital.

The form was developed in two steps:

1) A Healthcare Failure Mode and Effect Analysis (HFMEA) of the rescue operation process was performed in order to identify all critical phases associated with a risk for error, as well as all errorrelated causes.

2) All identified modes of errors were then used to create a list of items.

The final version of the form included six different phases: 1) emergency call, 2) identification of event site, 3) dispatch (severity code assignment), 4) resource allocation and timing, 5) clinical evaluation and transfer, and 6) delayed assistance or hospital admission. Each phase included a list of potential modes of error for a total of 30 items (see Appendix 1). In order to fill in the form, the participants had to select and sign off on the item(s) relating to the event being reported.

The form included a descriptive section to report any mistakes and/or error modes not considered in the 30-item list.

Before its implementation, the tool was used by a team of four expert nurses and two medical doctors in order to pinpoint any problems and misunderstandings in the phrasing of the various items. The group was asked to analyse a set of real cases and to report any errors by filling in the form. No changes to the initial form were necessary.

\section{Data collection}

The team was informed about the purpose of the project and invited to fill in the EMS failure report form whenever an error, near miss, or AE would be detected. The form was anonymous because the main aim was to learn from mistakes and implement suitable improvement strategies. Because this is a quality improvement project, using data collected as part of the routine care, no additional local ethics approval was requested.

The form included the following basic information:

1) Number identifying each medical emergency response

2) Level(s) of the process in which failure(s) occurred (phase)

3) Cause(s) of the malfunction (potential modes of error)
All of the EMS report forms relating to emergency calls followed by the dispatch of at least one emergency vehicle were included.

Each report was reviewed by an expert nurse directly involved in data collection in order to exclude any forms with unaccountable data.

\section{Main outcome measures}

The main outcome measures were: 1) participant satisfaction with the IR system and 2) usefulness of the tool to guide the implementation of corrective measures (number of corrective measures implemented for the critical areas identified using the tool).

\section{Statistical analysis}

All data were analysed considering four different variables: 1) frequency of reported interventions, 2) phase, 3) causes (both human and technical factors), and 4) severity (degree of potential harm).

The classification of the 30 error modes into failures either due or not due to non-technical (human) factors was done by two researchers according to the definition given by Flin et al.: "non-technical skills (NTS) are defined as the cognitive social and personal resource skills that complement technical skills and contribute to safe and efficient task performance." 11

Three degrees of severity were considered, following an adapted version of the National Coordinating Council for Medication Error Reporting and Prevention (NCC MERP) classification system for categorizing medication errors ${ }^{12}$ :

- Mild: no potential consequences

- Moderate: potential temporary harm

- Severe: potential permanent harm or patient death

Results were then analysed by a working group in order to identify critical areas and adequate corrective measures.

Data collected were analysed using descriptive statistics.

\section{RESULTS}

The study was run for 268 consecutive days from February to November 2010. All staff working at the EMDC of Verona were involved. 


\section{Staff satisfaction with the IR system}

All participants were interviewed by the nurse responsible for data collection about their opinion of the implemented IR system. All of the staff reported that being directly involved in risk management had positive effects on patient safety. First, they felt more motivated to use errors as a learning opportunity and less fearful of reporting them. Second, they reported paying more attention to risky behaviors or situations. Third, they felt motivated to discuss any mistakes within the team in order to find solutions or preventive measures (with a positive effect also on teamwork).

\section{Frequency of reported failures}

All of the nurses filled in at least one form. During the 268-day period, 142 EMS failure report forms were collected, for a total of 161 error modes detected. Fifteen forms reported two error modes occurring during the same emergency response (11\%), while two forms reported three errors occurring concomitantly $(1 \%)$.

During the same period, the EMDC received a total of 46,584 emergency calls followed by the dispatch of an emergency vehicle. The error rate was 3.5 per 1,000 ambulance dispatches.

\section{Phase (at what level in the process that the malfunction occurred)}

As shown in Table 1, the most frequent errors were related to resource allocation and timing $(34.2 \%)$ and to dispatch $(31.0 \%)$.

\section{Influence of human factors}

Of 161 detected errors, 125 were errors related to human factors $(77.6 \%)$ (Table 1$)$.

\section{Severity (degree of potential harm)}

$52 \%$ (no. 84) of the error modes were classified as mild, $28 \%$ (no. 45 ) as moderate, and $20 \%$ (no. 32 ) as potentially severe.

\section{Main critical areas and corrective measures identified}

Table 2 summarizes the main critical areas defined by error modes with the highest occurrence $(\geq 5 \%)$.
The relevant corrective actions implemented are reported in the table.

\section{DISCUSSION}

\section{Main findings}

The majority of errors occurred during the central phases of the rescue operation process (phase 3, dispatch and phase 4, resource allocation and timing), consistent with other data in the literature. A study on IR implementation in prehospital settings identified clinical judgment and dispatch issues together with staffing/ ambulance availability as two of the most reported problems. ${ }^{4}$ Another study on health providers' perceptions of key issues in prehospital settings, evidenced poor clinical judgment as a critical issue, underlying the need for specific training. ${ }^{13}$ Similar results are confirmed by a systematic review conducted on this topic. ${ }^{6}$

With regard to the dispatching phase, most of the problems seem to be related to inefficient communication with the caller (not able to see/interact/evaluate the person in need of help or reporting unrealistic data). Almost $4 \%$ of errors were due to a mistaken evaluation of the data (provided during the emergency call). The dispatch phase has been improved through the adoption of an updated version of the Medical Priority Dispatch System. Compared with the previous version (based on a single flow chart to be adopted in all situations), the new version identifies a limited number of critical areas with a specific flow chart for each area. The software EMMA $^{\odot}$ (Emergency Management Mapping Application) guides the professional with a structured sequence of key questions, each associated with a specific set of answers. Based on the answer, the nurse assesses whether patient symptoms are associated with a severe condition. Each step is mandatory. In order to facilitate severity code assignment, a visual pattern has been developed, including information on 1) main diagnosis for each area with the corresponding severity color code (red, yellow, or green); 2) main scales used in the emergency setting (e.g., Glasgow Coma Scale, Cincinnati prehospital score); 3) major trauma criteria identification; 4) burn severity system identification; and 5) normal vital signs and major alterations. A specific section is dedicated to pediatric problem management. This approach allows staff to ask more appropriate questions, to better understand the situation, and to decide more quickly and efficiently what response 


\begin{tabular}{|c|c|c|c|c|}
\hline Stage & Critical area & Error modes & N (\%) & $\begin{array}{c}\text { Human factors (yes/ } \\
\text { no; N/\%) }\end{array}$ \\
\hline 1. Emergency call & $\begin{array}{l}\text { User communication } \\
\text { problems }\end{array}$ & $\begin{array}{l}\text { Call waiting: no dispatchers available } \\
\text { Phone malfunction } \\
\text { Phone call interruption } \\
\text { Phone connection (line) problems } \\
\text { User confused and/or not clear } \\
\text { Language difficulties }\end{array}$ & $\begin{array}{c}0(0) \\
1(0.6) \\
0(0) \\
2(1.2) \\
3(1.9) \\
5(3.1) \\
\mathbf{1 1}(\mathbf{6 . 8 )}\end{array}$ & $\begin{array}{l}\text { No } \\
\text { No } \\
\text { No } \\
\text { No } \\
\text { Yes } \\
\text { Yes } \\
\mathbf{8}(\mathbf{5 \% )}\end{array}$ \\
\hline $\begin{array}{l}\text { 2. Event site } \\
\text { identification } \\
\text { Total }\end{array}$ & $\begin{array}{l}\text { Incorrect identification of } \\
\text { event site }\end{array}$ & $\begin{array}{l}\text { Address transcription error, misunderstanding, address forgotten } \\
\text { Streets or villages with the same name } \\
\text { Too many interlocutors complicating the information flow } \\
\text { Difficult phone and/or radio communication }\end{array}$ & $\begin{aligned} 6 & (3.7) \\
11 & (6.8) \\
1 & (0.6) \\
0 & (0) \\
\mathbf{1 8} & (\mathbf{1 1 . 2})\end{aligned}$ & $\begin{array}{l}\text { Yes } \\
\text { No } \\
\text { Yes } \\
\text { No } \\
\mathbf{7}(\mathbf{4 . 3} \%)\end{array}$ \\
\hline $\begin{array}{l}\text { 3. Dispatch } \\
\text { Total }\end{array}$ & $\begin{array}{l}\text { Inappropriate severity code } \\
\text { assignment }\end{array}$ & $\begin{array}{l}\text { Mistaken evaluation of the data (provided during the emergency call) } \\
\text { Caller not capable of reporting clear data } \\
\text { Caller not able to see/interact/evaluate the person in need of help } \\
\text { Caller reporting unrealistic data } \\
\text { Usual callers }\end{array}$ & $\begin{aligned} 6 & (3.7) \\
4 & (2.5) \\
10 & (6.2) \\
30 & (18.6) \\
0 & (0) \\
\mathbf{5 0} & (\mathbf{3 1 . 0})\end{aligned}$ & $\begin{array}{l}\text { Yes } \\
\text { Yes } \\
\text { Yes } \\
\text { Yes } \\
\text { Yes } \\
\mathbf{5 0}(\mathbf{3 1 \% )}\end{array}$ \\
\hline $\begin{array}{l}\text { 4. Resource allocation } \\
\text { and timing }\end{array}$ & $\begin{array}{l}\text { Inappropriate resource } \\
\text { allocation }\end{array}$ & $\begin{array}{l}\text { Incorrect or mistaken information regarding the event site } \\
\text { Inappropriate emergency vehicle in relation to geographical and/or weather } \\
\text { conditions (specify in the notes) } \\
\text { Difficulties related to road conditions } \\
\text { Difficulties with names of places } \\
\text { Poor familiarity with the area } \\
\text { Vehicle or road damage } \\
\text { Delayed departure of the rescue vehicle } \\
\text { Traffic accident: interruption or delay (specify in the notes) }\end{array}$ & $\begin{aligned} 9 & (5.6) \\
2 & (1.2) \\
2 & (1.2) \\
7 & (4.3) \\
4 & (2.5) \\
6 & (3.7) \\
22 & (13.7) \\
3 & (1.9) \\
\mathbf{5 5} & (\mathbf{3 4 . 2})\end{aligned}$ & $\begin{array}{l}\text { Yes } \\
\text { Yes } \\
\text { No } \\
\text { No } \\
\text { Yes } \\
\text { No } \\
\text { Yes } \\
\text { Yes } \\
\mathbf{4 0} \mathbf{( 2 4 . 8 \% )}\end{array}$ \\
\hline $\begin{array}{l}\text { 5. Clinical evaluation/ } \\
\text { transfer }\end{array}$ & $\begin{array}{l}\text { Inappropriate severity } \\
\text { evaluation } \\
\text { Patient transfer to an } \\
\text { inappropriate hospital }\end{array}$ & $\begin{array}{l}\text { Underestimation/Overestimation } \\
\text { Complex event } \\
\text { Bad weather condition } \\
\text { Inappropriate clinical evaluation } \\
\text { Missing or inappropriate communication about the event to the EMDC (by rescuers) }\end{array}$ & $\begin{array}{ll}8 & (5) \\
1 & (0.6) \\
0 & (0) \\
2 & (1.2) \\
6 & (3.7) \\
\mathbf{1 7} & (\mathbf{1 0 . 6 )}\end{array}$ & $\begin{array}{l}\text { Yes } \\
\text { No } \\
\text { No } \\
\text { Yes } \\
\text { Yes } \\
\mathbf{1 6} \mathbf{( 9 . 9 \% )}\end{array}$ \\
\hline $\begin{array}{l}\text { 6. Assistance/hospital } \\
\text { admission } \\
\text { Total } \\
\text { TOTAL }\end{array}$ & $\begin{array}{l}\text { Delayed assistance/hospital } \\
\text { admission }\end{array}$ & $\begin{array}{l}\text { Due to problems occurring at the EMDC (too many emergency calls, complex } \\
\text { events, ...) } \\
\text { Inappropriate management of the call by the dispatcher }\end{array}$ & $\begin{array}{r}6(3.7) \\
4(2.5) \\
10(6.2) \\
161(100)\end{array}$ & $\begin{aligned} & \text { No } \\
\text { Yes } & \\
\mathbf{4} & (\mathbf{2 . 6 \% )} \\
\mathbf{1 2 5} & (\mathbf{7 7 . 6 \% )}\end{aligned}$ \\
\hline
\end{tabular}




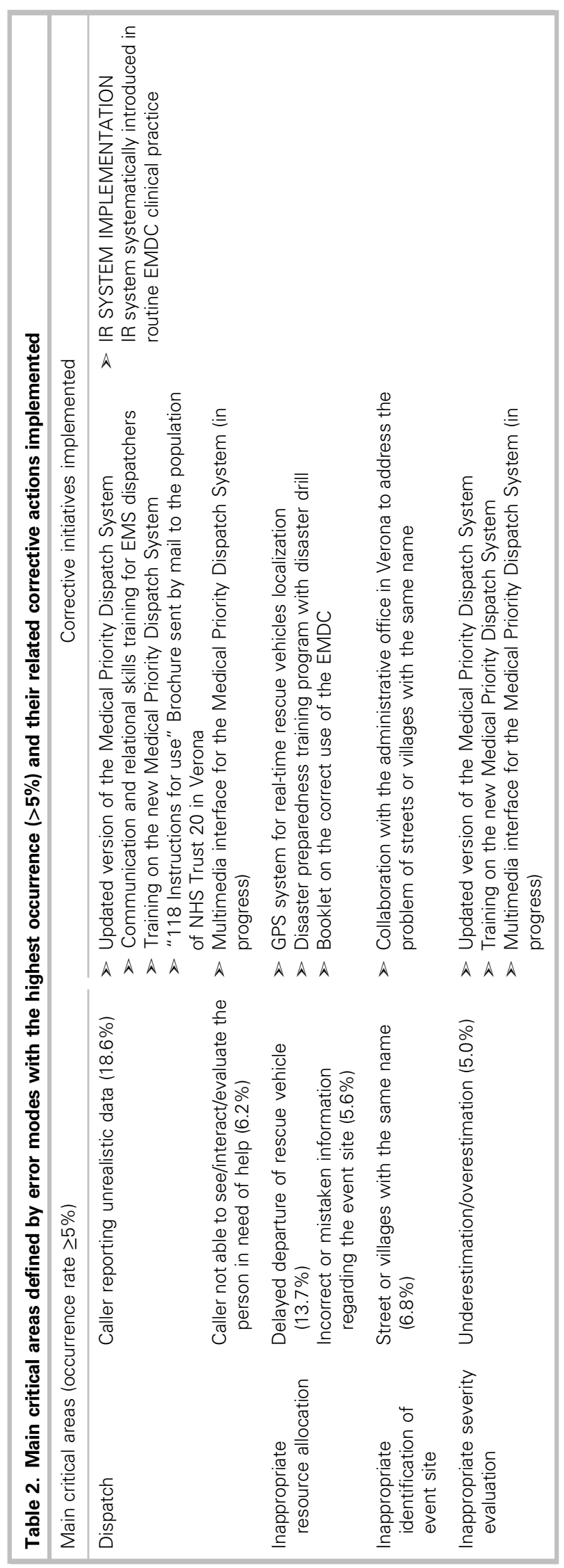

needed dispatching. This system can add several advantages, such as an improvement in dispatcher-caller communications, a more structured assessment of patient severity conditions, better stress management, better coordination between the EMDC and the rescue team, and better resource allocation. The system would be further improved by implementing a multimedia interface capable of capturing images or video recordings via the caller's mobile phone. This could help overcome misunderstandings due to verbal difficulties but would have to first pass legal consideration over patient confidentiality issues.

In this particular phase, an essential role is also played by the caller. A brochure explaining the role of 118 EMS (118 Instructions for Use) and translated into eight languages was sent by regular mail to all of the families living in the area of NHS Trust 20 of Verona. The booklet informs the public on when and how to call the EMS, and provides basic core information. The brochure is available for download on the website of NHS Trust 20 of Verona. With regard to phase 4 (resource allocation and timing), an important role is played by the delayed departure of the rescue vehicle. As defined by Cooney et al., the ambulance offload delay is the time that "it takes to transfer a patient to an ED stretcher and for the ED staff to assume the responsibility for the care of the patient." ${ }^{14}$ A delay occurring at this stage can have important consequences for patients and ambulance turnover. The ongoing implementation of the global positioning system (GPS) allows for continuous updating of vehicle localization so that the dispatcher can save valuable time coordinating vehicle allocation. Moreover, a program has been developed to train dispatchers on how to deal with mass casualty emergencies. The training includes both classroom and hands-on activities and is mostly focused on developing the dispatchers' coordination skills.

Errors during phase 5 occurred with a lower frequency. However, an inappropriate clinical evaluation can result in serious patient harm. ${ }^{15}$ Prehospital emergency care education needs to be carefully structured. Continuous feedback and information exchange meetings with senior dispatchers provided an opportunity to recognize hazardous behaviors and to adopt the most suitable corrective actions.

Finally, results show that the majority of mistakes $(78 \%)$ were due to human factors. Similar results are confirmed by the literature, ${ }^{16}$ evidencing the need to implement specific training on NTS. ${ }^{17,18}$ A specific 
course on communication and relational skills for the EMDC staff has been run to try and overcome these educational gaps.

The importance of adopting corrective actions is further confirmed by the evidence that almost half of the errors were moderate to severe. Risk management programs should be constantly implemented and integrated with the daily activities of the staff working in this setting.

Before the study, a single IR system was used for the entire NHS Trust 20. The project led to implementing an ad hoc form for the emergency care setting, thus promoting its ongoing use. The main results from the IR system are regularly analysed as part of clinical audits, in order to check for the efficacy of previously introduced corrective measures and to develop additional initiatives when necessary. The IR system has become an essential instrument in the development of a learning organization capable of implementing a continuous quality improvement system (plan-do-check-act system).

\section{Strengths and limitations of the study}

The main limitation of the study is the issue of underreporting. ${ }^{15,19,20}$ The results of our study show a very low error rate. Few studies analysed the results from the implementation of an IR system in prehospital settings, but no data on error rates are reported. These studies found very low numbers of collected reports, compared to our results, even during longer observational times. A UK study collected 124 reports along 8 months of study, whereas a U.S. study collected 415 reports during 7 years. ${ }^{4,21}$ One study showed that only half of EMS providers had reported an error in the previous year. ${ }^{20}$ These data confirm results from other researchers evidencing that error disclosure in the emergency medical setting represents a challenge for the staff. ${ }^{20,22,23}$

In order to further encourage the implementation of an IR system in this setting, it would be important to 1) develop an error classification system specific to the emergency prehospital stage and 2) ensure a national data flow of all mistakes collected within this setting. $^{24,25}$ These initiatives may guarantee the collection and analysis of many more data and foster comparisons across different organizations.

Nevertheless, many efforts were made to inform all participants about the aims of the project and the importance of reporting as many events as possible. In order to overcome the limitations intrinsic to the IR process, it could be useful to implement an additional tool measuring the errors occurring in this specific setting. For example, in other settings of NHS Trust 20, IR results are routinely compared with the Institute for Healthcare Improvement's Global Trigger Tool, which has not been designed for use in the emergency care setting.

Despite these limitations, the use of the form allowed a significant number of corrective measures to be implemented. Moreover, the improvement actions had a positive impact in all emergency management pathways from the site of intervention till the appropriate hospital care. Although the tool and the process were applied in the prehospital emergency care, the same methodology is sufficiently general to be adopted in any other medical setting.

\section{CONCLUSIONS}

Results suggest how the implementation of an efficient IR system may act as a major driver for the development of a "learning organization" and help overcome the blame and shame culture, which still affects many health care environments. Considering the low safety culture evidenced within this setting, the use of a prestructured instrument can help the staff develop a stronger critical thinking approach and promote continuous quality improvement.

Acknowledgements: The authors wish to thank all of the staff of the 118 EMDC of Verona for agreeing to participate in the study and for their essential collaboration.

Competing interests: None declared.

\section{SUPPLEMENTARY MATERIAL}

To view supplementary material for this article, please visit http://dx.doi.org/10.1017/cem.2014.74

\section{REFERENCES}

1. Hakimzada AF, Green RA, Sayan OR, et al. The nature and occurrence of registration errors in the emergency department. Int 7 Med Inform 2008;77(3):169-75.

2. Cooney DR, Millin MG, Carter A, et al. Ambulance diversion and emergency department offloads delay: resource document for the National Association of EMS physician position statement. Prehosp Emerg Care 2011; 15(4):555-61.

3. Hjalte L, Suserud BO, Herlitz J, et al. Why are people without medical needs transported by ambulance? A study of indications for pre-hospital care. Eur 7 Emerg Med 2007; 14(3):151-6. 
4. Gallagher JM, Kupas DF. Experience with an anonymous web-based state EMS safety incident reporting system. Prehosp Emerg Care 2012;16(1):36-42.

5. O'Connor RE, Slovis CM, Hunt RC, et al. Eliminating errors in emergency medical services: realities and recommendations. Prehosp Emerg Care 2006;6(1):107-13.

6. Bigham BL, JEs Buick, Brooks SC, et al. Patient safety in emergency medical services: a systematic review of the literature. Prehosp Emerg Care 2012;16(1):20-35.

7. Patterson PD, Huang DT, Fairbanks RJ, et al. Variation in emergency medical service workplace safety culture. Prehosp Emerg Care 2010;14(4):448-60.

8. Sticchi L, Gasparini R, Durando P, et al. First Aid Healthcare interventions Operations Centres (118) in Italy. 7PMH 2004:45:27-30.

9. Ministero della salute. Sistema di Emergenza territoriale "118." Rilevazione Nazionale Anno 2005. Available at: http://www.salute.gov.it/imgs/C_17_pubblicazioni_845_ allegato.pdf (accessed June 26, 2014).

10. Toniolo F, Mantoan D, Maresso A. Veneto Region, Italy: Health system review. Health Syst Transit 2012;14(1):1-138.

11. Flin R, Martin L, Goeters KM, et al. Development of the NOTECHS (non-technical skills) system for assessing pilots' CRM skills. Hum Fact Aerospace Safety 2003;3:97-119.

12. National Coordinating Council for Medication Error Reporting and Prevention (NCC MERP) Index for categorizing errors. Available at: http://www.nccmerp.org/ medErrorCatIndex.html (accessed January 10, 2013).

13. Atack L, Maher J. Emergency medical and health providers perceptions of key issues in pre-hospital patient safety. Prehosp Emerg Care 2010;14(1):95-102.

14. Rinke ML, Dietrich E, Kodeck T, et al. Operation care: a pilot case management intervention for frequent emergency medical system users. Am 7 Emerg Med 2012;30(2):352-7.
15. Cupera J, Mannovà J, Rihòvà H, et al. Quality of prehospital management of patients with burn injuries. A retrospective study. Acta Chir Plast 2002;44(2):59-62.

16. Fletcher GCL, McGeorge P, Flin RH, et al. The role of non-technical skill in anesthesia: a review of current literature. BM7 2002;88(3):418-29.

17. Flin R, Maran N. Identifying and training non-technical skills for teams in acute medicine. Qual Saf Health Care 2004;13(S1):i80-4.

18. Gurses AP, Ozok AA, Pronovost PJ. Time to accelerate integration of human factors and ergonomics in patient safety. BM7 Qual Saf 2012;21(4):347-51.

19. Evans SM, Berry JB, Smith BJ, et al. Attitudes and barriers to incident reporting: a collaborative hospital study. Qual Saf Health Care 2006;15(1):39-43.

20. Hobgood C, Bowen JB, Brice JH, et al. Do EMS personnel identify, report, and disclose medical errors. Prehosp Emerg Care 2006;10(1):21-7.

21. Shaw R, Drever F, Huges H, et al. Adverse events and near miss reporting in the NHS. Qual Saf Health Care 2005; 14(4):279-83.

22. Lu DW, Guenther E, Wesley AK, et al. Disclosure of harmful medical errors on out-of-hospital care. Ann Emerg Med 2013;61(2):215-21.

23. Jennings PA, Stella J. Barriers to incident notification in a regional prehospital setting. Emerg Med 7 2010; 28(6):526-9.

24. Bigham BL, Bull E, Morrison M, et al. Patient safety in emergency medical services: executive summary and recommendations from the Niagara summit. CFEM 2011; 13(1):13-8.

25. Mears G, Ornato JP, Dawson DE. Emergency medical services information systems and a future EMS national database. Prehosp Emerg Care 2004;6(1):123-30. 